\title{
Erratum to: Evaluation of the diagnostic performance of heart-type fatty acid binding protein in the BWH-TIMI ED chest pain study
}

\author{
Christian T. Ruff - Marc P. Bonaca · Joshua M. Kosowsky • \\ Michael J. Conrad · Sabina A. Murphy • Petr Jarolim • \\ Sean M. Donahoe $\cdot$ Michelle L. O'Donoghue $\cdot$ David A. Morrow
}

Published online: 23 October 2013

(c) Springer Science+Business Media New York 2013

Erratum to: J Thromb Thrombolysis

DOI 10.1007/s11239-013-0870-7

The author of this article would like to acknowledge the generosity of the Harris Family who supported the project through the J. Ira and Nicki Harris Family Research Scholarship in the "Acknowledgments" section of the original publication.

The online version of the original article can be found under doi:10.1007/s11239-013-0870-7.

C. T. Ruff $(\bowtie) \cdot$ M. P. Bonaca · S. A. Murphy ·

M. L. O'Donoghue - D. A. Morrow

TIMI Study Group, Cardiovascular Division,

Department of Medicine, Brigham and Women's Hospital,

Harvard Medical School, 350 Longwood Avenue,

1st Floor Offices, Boston, MA 02115, USA

e-mail: cruff@partners.org

J. M. Kosowsky

Department of Emergency Medicine, Brigham and Women's

Hospital, Boston, MA, USA

M. J. Conrad · P. Jarolim

Department of Pathology, Brigham and Women's Hospital,

Harvard Medical School, Boston, MA, USA

S. M. Donahoe

Eastern Suffolk Cardiology, Stony Brook Community Medical,

Southampton, NY, USA 